\title{
Identification of the amino-acetonitrile derivative monepantel (AAD 1566) as a new anthelmintic drug development candidate
}

\author{
R. Kaminsky • N. Gauvry • S. Schorderet Weber • \\ T. Skripsky • J. Bouvier • A. Wenger • F. Schroeder • \\ Y. Desaules • R. Hotz • T. Goebel • B. C. Hosking • \\ F. Pautrat $\cdot$ S. Wieland-Berghausen $\cdot$ P. Ducray
}

Received: 26 May 2008 / Accepted: 2 June 2008 / Published online: 2 July 2008

(C) The Author(s) 2008

\begin{abstract}
Anthelmintic resistance has become a global phenomenon in gastro-intestinal nematodes of farm animals, including multi-drug resistance against the three major classes of anthelmintics. There is an urgent need for an anthelmintic with a new mode of action. The recently discovered amino-acetonitrile derivatives (AADs) offer a new class of synthetic chemicals with anthelmintic activity. The evaluation of AADs was pursued applying in vitro assays and efficacy and tolerability studies in rodents, sheep, and cattle. Amongst various suitable compounds, AAD 1566 eliminated many tested pathogenic nematode species, both at larval and adult stages, at a dose of $2.5 \mathrm{mg} / \mathrm{kg}$ bodyweight in sheep and $5.0 \mathrm{mg} / \mathrm{kg}$ bodyweight in cattle. The same doses were sufficient to cure animals infected with resistant or multi-drug-resistant nematode isolates. These findings, complemented by the good tolerability and low toxicity to mammals, suggest that AAD 1566, monepantel, would be a suitable anthelmintic drug development candidate.
\end{abstract}

R. Kaminsky $(\bowtie) \cdot S$. Schorderet Weber $\cdot$ J. Bouvier

A. Wenger $\cdot$ F. Schroeder $\cdot$ Y. Desaules $\cdot$ R. Hotz

Novartis Centre de Recherche Santé Animale,

CH-1566 St. Aubin, Switzerland

e-mail: ronald.kaminsky@novartis.com

N. Gauvry • T. Skripsky • T. Goebel • F. Pautrat •

S. Wieland-Berghausen $\cdot$ P. Ducray

Novartis Animal Health Inc.,

CH-4002 Basel, Switzerland

B. C. Hosking

Novartis Animal Health Australasia Pty Limited,

Yarrandoo R \& D Centre,

245 Western Road, Kemps Creek,

Sydney, NSW 2178, Australia

\section{Introduction}

Today, chemotherapy of nematode infections in livestock mainly relies on three classes of broad-spectrum anthelmintics, the benzimidazoles (BZs), imidothiazoles (LEV), and macrocyclic lactones (MLs). From these, the latest class introduced to the market were the MLs in 1981 (Chabala et al. 1980). The frequent use of these anthelmintics over many years has inevitably led to the development of drug resistance to each class in parasitic nematodes. While reports of anthelmintic resistance in cattle nematodes started to accumulate in recent years (Coles et al. 2001, Familton et al. 2001, Mejia et al. 2003, Anziani et al. 2004, Gasbarre and Smith 2004, Waghorn et al. 2006a), resistance in sheep nematodes is more established and continues to increase in prevalence and severity in most sheep-farming regions of the world (Coles et al. 1991, Echevarria et al. 1996, van Wyk et al. 1997, Coles 1998, Jackson and Coop 2000, Love et al. 2003, Kaplan 2004, Waghorn et al. 2006b, Traversa et al. 2007). The appearance of multi-drug-resistant nematode isolates is threatening successful chemotherapy of infected sheep in many countries (Yue et al. 2003, Kaminsky 2003, Besier and Love 2003, Wrigley et al. 2006). This has serious consequences and in some cases has even resulted in flock closure (Sargison et al. 2005, Blake and Coles 2007). Integrated parasite management approaches have recently been considered important in parasite control (Waller 1999) but so far have not shown sufficient effect without using suitable supportive anthelmintic therapy (Besier 2007). However, no new anthelmintic class has been introduced to the market within the last 28 years, with the exception of the cyclodepsipeptides, which to date are only licensed for use in cats to control nematodes. Besier (2007) describes the situation for sheep farmers as "sitting on a hypothetical 
nematode-control time bomb with a shortening fuse". Clearly, there is an urgent need for new anthelmintics for livestock, which are able to overcome resistance to the currently available drugs. Most recently, the amino-acetonitrile derivatives (AADs) were discovered to express anthelmintic activity (Kaminsky et al. 2008). AADs are a class of low molecular mass compounds bearing different aryloxy and aroyl moieties on an amino-acetonitrile core (Ducray et al. 2008). They offer a class of novel synthetic compounds with high activity against all gastro-intestinal nematodes, including resistant isolates (Kaminsky et al. 2008), an essential prerequisite for any potential new anthelmintic drug. To identify a suitable drug development candidate amongst the whole class of AADs, in vitro assays and efficacy and tolerability studies in rodents, sheep, and cattle were pursued.

\section{Materials and methods}

Nematode isolates The origin, history, and drug sensitivity status of nematode isolates used are summarized in Table 1. Most of the susceptible isolates were continuously passaged in sheep or cattle for many years at the Novartis Centre de Recherche Santé Animale (Switzerland). In addition, four drug-resistant isolates were used. The Haemonchus contortus Howick isolate (van Wyk et al. 1997) was received from Dr. J. van Wyk, Onderstepoort Veterinary Institute. The Howick isolate is multi-drug-resistant to BZs, MLs, and LEV (van Wyk et al. 1997, Ghisi et al. 2007). The Australian $H$. contortus Mox/Fen isolate was kindly provided by G. Hutchinson, New South Wales Department of Primary Industries. This isolate is resistant to at least the MLs and BZs (Love et al. 2003). The H. contortus Courtion and Trichostrongylus colubriformis Villarey were both isolated in
2004 from farms near the Novartis Centre de Recherche Santé Animale in the Canton Fribourg, Switzerland. $H$. contortus Courtion is resistant to BZs, and T. colubriformis Villarey is resistant to BZs and LEV (Kaminsky et al. 2008).

In vitro assays The in vitro larval development assay was performed as described by Gill et al. (1995), with minor modifications. Briefly, freshly harvested and cleaned nematode eggs were used to seed a suitably formatted 96well plate containing the test substances to be evaluated for anthelmintic activity. Each compound was tested by serial dilution in order to determine the effective concentration $\left(\mathrm{EC}_{100}\right)$, which eliminates all nematodes. The test compounds were embedded in an agar-based nutritive medium, allowing the full development of eggs through to third stage larvae (L3). The plates were incubated for 6 days at $28^{\circ} \mathrm{C}$ and $80 \%$ relative humidity. Nematodicidal activity was expressed as percent reduced development of L3 stages. The AADs were tested against drug susceptible and BZresistant $H$. contortus.

Efficacy testing in Meriones unguiculatus Evaluation in gerbils was performed according to Conder et al. (1990, 1991), with minor modifications. Gerbils were artificially infected by gavage with ca. 2,500 sheathed L3 larvae each of T. colubriformis and H. contortus, 6 and 5 days before treatment, respectively. Treatment with AAD compounds was performed orally by gavage or subcutaneously by injection. Control animals received a placebo formulation. Three days after treatment, gerbils were euthanized and dissected to recover $H$. contortus and $T$. colubriformis. After incubation of the organs for $2 \mathrm{~h}$ at $37^{\circ} \mathrm{C}$, worms ( $\mathrm{L} 4$ stage) were collected in water, stained with iodine, and counted using a stereomicroscope. Efficacy was expressed as a percentage reduction in worm numbers in comparison

Table 1 Origin and drug sensitivity status of nematode isolates in sheep

\begin{tabular}{llll}
\hline Species & Origin & Isolated in or maintained since & Drug resistance to \\
\hline Haemonchus contortus susc & South Africa & 1984 & susc \\
H. contortus Howick & South Africa, Howick & 1997 & BZs, LEV, MLs \\
H. contortus Courtion & Switzerland, Courtion & 2004 & BZs \\
H. contortus Mox/Fen & Australia & 2003 & BZs, MLs \\
Trichostrongylus colubriformis susc & UK, Weybridge & 1989 & susc \\
T. colubriformis Villarey & Switzerland, Villarey & 2004 & BZs, LEV \\
T. axei & UK, Weybridge & 1989 & susc \\
Teladorsagia circumcincta & UK, Glasgow & 1988 & susc \\
Cooperia curticei & UK, Weybridge & 1991 & susc \\
Nematodirus spathiger & UK, Weybridge & 1989 & susc \\
Chabertia ovina & Germany, Hannover & 1993 & susc \\
Ostertagia ostertagi & UK, Glasgow & 1999 & susc \\
C. oncophora & UK, Glasgow & 1999 & susc \\
\hline
\end{tabular}

$B Z s$ Benzimidazoles, $L E V$ imidazothiozoles (levamisole), $M L s$ macrocyclic lactones, susc susceptible 
with the geometric mean of worms collected from the control group using Abbott's formula.

Efficacy studies in sheep and cattle Sheep and cattle efficacy studies were performed according to the guidelines for evaluating the efficacy of anthelmintics in ruminants (bovine, ovine, caprine) by the World Association for the Advancement of Veterinary Parasitology (Wood et al. 1995).

Ames test The study was performed as plate incorporation test and as pre-incubation test according to the OECD (1997a) guideline for the testing of chemicals 471 using the Salmonella typhimurium strains TA 1535, TA 97A, TA 98, TA 100, and TA 102. Both independent tests were performed with and without liver microsomal activation (S9 mix). Each AAD concentration, including the positive and negative controls, was tested in triplicate.

Chromosome aberration test The study was performed according to OECD (1997c) guideline for the testing of chemicals 473 in order to evaluate any clastogenic potential of a compound in vitro. This was done by determining the effect of the test item on the frequency of chromosomal aberrations in cultured human peripheral blood lymphocytes in the presence and absence of rat liver S9.

Micronucleus test The test was performed according to OECD (1997b) guideline for the testing of chemicals 474. Administration of the compound was via gavage. Two repeated doses of 2,000 $\mathrm{mg} / \mathrm{kg}$ bodyweight each, $24 \mathrm{~h}$ apart, were administered to five male and five female mice per group. Mice were killed $24 \mathrm{~h}$ after the second dose. Bone marrow was collected from the femoral bone. The ratio of polychromatic/normochromatic erythrocytes (PCE/NCE) was determined by counting at least 1,000 erythrocytes, and the micronuclei were counted in at least 2,000 polychromatic erythrocytes.

Tolerability tests Six sheep of the brown Alp breed weighing between $30-50 \mathrm{~kg}$ were used. Sheep were treated on day 0 according to individual bodyweights assessed 5 days before compound administration. The AADs 85 and 96 were administered orally by syringe to the back of the throat of two sheep each at a dose of $50 \mathrm{mg}$ racemate $/ \mathrm{kg}$. A placebo formulation was administered at a similar volume to the two sheep in the control group. After treatment, the animals were observed at least once a day for the remainder of the study regarding their general health and behavior. In addition, bodyweights, food consumption, clinical chemistry, hematology, heart rate, and body temperature were evaluated up to day 14 after dosing.

A second study was undertaken to examine the tolerability of the active enantiomer AAD 1566. Six Suffolk female sheep (aged 11 months) were allocated to three groups of two sheep each, one of which served as an untreated control. On day 0 , two sheep were treated with AAD 1566 at $50 \mathrm{mg} / \mathrm{kg}$, which was two times the dose used in the previous study. Seven days later, two other sheep were treated with the same formulation at $75 \mathrm{mg} / \mathrm{kg}$. Following their successful treatment, the sheep treated with $50 \mathrm{mg} / \mathrm{kg}$ were re-treated at $100 \mathrm{mg} / \mathrm{kg}$ on day 14 . Similarly, the sheep treated previously with $75 \mathrm{mg} / \mathrm{kg}$ were re-treated on day 21 at $125 \mathrm{mg} / \mathrm{kg}$. The following measurements were taken throughout the study: visual observations including veterinary examinations, daily food intake, bodyweights, clinical blood chemistry and hematology, and body temperature.

\section{Results}

The AADs evaluated herein were derived from an optimization program (Ducray et al. 2008) and showed in vitro $\mathrm{EC}_{100}$ values between 0.01 and $0.04 \mu \mathrm{g} / \mathrm{mL}$ (individual data not shown). The in vitro susceptibility was similar for $H$. contortus and $T$. colubriformis and was independent of the sensitivity status of the nematode isolate.

When tested in gerbils, all AADs evaluated herein had an efficacy of $85-100 \%$ at an oral dose of $1 \mathrm{mg} / \mathrm{kg}$ against $H$. contortus susc and T. colubriformis susc (Table 2). Differences occurred at a dose of $0.32 \mathrm{mg} / \mathrm{kg}$, when most AADs were not active against $T$. colubriformis susc (except AAD 96). The efficacy of AADs after subcutaneous application of $1 \mathrm{mg} / \mathrm{kg}$ was only slightly lower if not similar to that observed after oral application (Table 2). After separation of the racemic mixture of AAD 96, the two resulting enantiomers were tested against drug-resistant nematode isolates (Table 3). The racemic mixture AAD 96 showed $84-100 \%$ efficacy at $1 \mathrm{mg} / \mathrm{kg}$ when applied orally or subcutaneously. At the same doses, the enantiomer AAD 1566 showed a higher activity (99-100\%) while the other enantiomer AAD 96i did not show any activity (Table 3). Furthermore, the AAD 1566 and the enantiomer AAD 85a, the active enantiomer of AAD 85, were both effective against the multi-drug-resistant $H$. contortus Howick isolate in gerbils (Table 4). While a dose of $10 \mathrm{mg} / \mathrm{kg}$ albendazole, $0.2 \mathrm{mg} / \mathrm{kg}$ ivermectin, or $10 \mathrm{mg} / \mathrm{kg}$ levamisole cured all gerbils infected with $H$. contortus susc, none of the gerbils infected with the $H$. contortus Howick was cured. On the contrary, the activity of AAD 85a and AAD 1566 at an oral dose of $0.5 \mathrm{mg} / \mathrm{kg}$ was similar against both the Howick isolate and the susceptible isolate (Table 4).

All AADs tested were active against the larval (L4) stage of most nematode species in sheep at an oral dose of $5 \mathrm{mg}$ active enantiomer $/ \mathrm{kg}$ (Table 5). AAD 85 and AAD 96 were $92-100 \%$ effective against all species tested 
Table 2 Efficacy of AADs in gerbils ( $\mathrm{n}=2$ ) against the susceptible isolates H. contortus susc (South Africa; Hc) and T. colubriformis susc (UK; Tc)

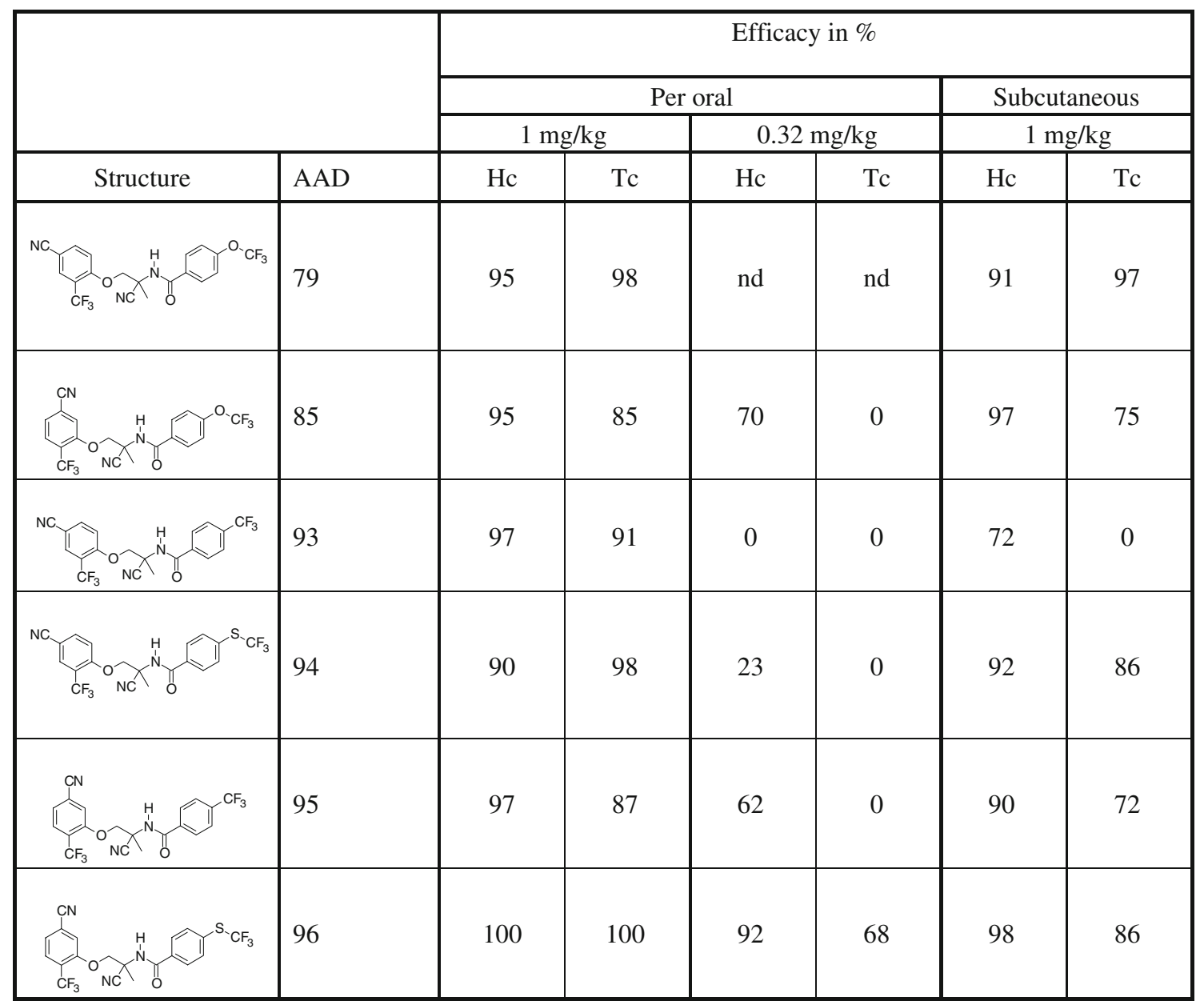

The doses are for the racemic mixture of each $\mathrm{AAD}$ containing equal amounts of active and inactive enantiomers. nd Not done

at a dose of $2.5 \mathrm{mg}$ active enantiomer $/ \mathrm{kg}$. At lower doses, the efficacy decreased for Cooperia curticei and Nematodirus spathiger to below 90\%. The efficacy of AAD 1566, the active enantiomer of the racemic mixture AAD 96, against all species tested (L4 stages) was above 96\% at an oral dose of $2.5 \mathrm{mg} / \mathrm{kg}$ (Table 5). The same dose was sufficient to cure all sheep infected with adult stages of either the multi-drug-resistant $H$. contortus Howick or the H. contortus Australian Mox/Fen isolate (Table 6). These isolates were not eliminated from sheep when treated with $0.2 \mathrm{mg} / \mathrm{kg}$ ivermectin or moxidectin, respectively, and neither were eliminated with a combination of ivermectin plus albendazole plus levamisole nor with a combination of moxidectin plus fenbendazole plus levamisole at the recommended doses, respectively. AAD 96 cured infected sheep with each of the two isolates at a dose down to $1.25 \mathrm{mg}$ active enantiomer/kg (Table 6).

AAD 96 was also tested against adult stages of various nematode species. Sheep infected with $H$. contortus,
Teladorsagia circumcincta, T. axei, T. colubriformis, $C$. curticei, N. spathiger, and Chabertia ovina were treated 29 days after infection, by which time the infections had matured so that all sheep had high nematode eggs per gram feces (epg). Three sheep each were treated with 5.0, 2.5, and $1.25 \mathrm{mg}$ racemate $/ \mathrm{kg}$ corresponding to $2.5,1.25$, and $0.63 \mathrm{mg}$ active enantiomer $/ \mathrm{kg}$ bodyweight. In all treated sheep, the epg decreased substantially within the first 2 days (Fig. 1). The epg of sheep treated with 2.5 and $1.25 \mathrm{mg}$ active enantiomer $/ \mathrm{kg}$ remained negative until day 20 posttreatment. Two sheep treated with $0.63 \mathrm{mg}$ active enantio$\mathrm{mer} / \mathrm{kg}$ remained negative, while one sheep, the epg became positive at very low level (maximum of $100 \mathrm{epg}$ ) compared to the untreated control sheep (Fig. 1). Efficacy based on worm counts after necropsy were $99-100 \%$ for all species in sheep treated with $2.5 \mathrm{mg}$ active enantiomer $/ \mathrm{kg}$ and $96-$ $100 \%$ for most species treated with $1.25 \mathrm{mg} / \mathrm{kg}$. In the latter group, which had a negative epg, the efficacy for N. spathiger was $87 \%$ and $79 \%$ for C. ovina. 
Table 3 Efficacy of the racemic mixture AAD 96 and the two enantiomers, AAD 1566 and AAD 96i, against the drug-resistant isolates $H$. contortus Courtion (HcC) and T. colubriformis Villarey (TcV) in gerbils $(n=2)$

\begin{tabular}{|c|c|c|c|c|c|c|}
\hline & \multicolumn{6}{|c|}{ Efficacy (\%) } \\
\hline & \multicolumn{4}{|c|}{ Per oral } & \multirow{2}{*}{\multicolumn{2}{|c|}{$\frac{\text { Subcutaneous }}{1 \mathrm{mg} / \mathrm{kg}}$}} \\
\hline & \multicolumn{2}{|c|}{$1 \mathrm{mg} / \mathrm{kg}$} & \multicolumn{2}{|c|}{$0.32 \mathrm{mg} / \mathrm{kg}$} & & \\
\hline Compound & $\mathrm{HcC}$ & $\mathrm{TcV}$ & $\mathrm{HcC}$ & $\mathrm{TcV}$ & $\mathrm{HcC}$ & $\mathrm{TcV}$ \\
\hline AAD 96 & 100 & 95 & 76 & 17 & 100 & 84 \\
\hline $\begin{array}{l}\text { AAD } 1566 \\
\text { CN }\end{array}$ & 100 & 100 & 100 & 88 & 100 & 99 \\
\hline & 0 & 0 & 6 & 0 & 15 & 0 \\
\hline
\end{tabular}

Four AADs were tested for efficacy in cattle. AAD 96 cured cattle infected with larval stages of Ostertagia ostertagi and C. oncophora at an oral dose of $7.5 \mathrm{mg}$ active enantiomer $/ \mathrm{kg}$ and had an efficacy of $98-100 \%$ at a dose of $3.8 \mathrm{mg} / \mathrm{kg}$. AAD 1566 eliminated all adult $O$. ostertagi and $C$. oncophora when applied topically at a dose of $5 \mathrm{mg} / \mathrm{kg}$ (Table 7).

The most efficacious AADs were tested for mutagenic, clastogenic, or aneugenic potential using the Ames test, the in vitro chromosome aberration test with human cells, and the mouse micronucleus test.

Ames test AAD 1566 precipitated on the test plates at $5,000 \mu \mathrm{g} /$ plate (plate incorporation) or at $\geq 200 \mu \mathrm{g} / \mathrm{plate}$ (pre-incubation). No evidence of bacteriotoxicity was

Table 4 Efficacy of the active enantiomers AAD 85a and AAD 1566 after oral application against multi-drug-resistant $H$. contortus (Howick) in gerbils

\begin{tabular}{lccc}
\hline Drug & $\begin{array}{l}\text { Dose } \\
(\mathrm{mg} / \mathrm{kg})\end{array}$ & $\begin{array}{l}\text { Efficacy (\%) against } \\
\text { H. contortus susc }\end{array}$ & $\begin{array}{l}\text { Efficacy (\%) against } \\
\text { H. contortus Howick }\end{array}$ \\
\hline Albendazole & 10 & 100 & 39 \\
Ivermectin & 0.2 & 100 & 35 \\
Levamisole & 10 & 100 & 51 \\
AAD 85a & 0.5 & 97 & 97 \\
AAD 1566 & 0.5 & 100 & 100 \\
\hline
\end{tabular}

Each dose was tested with six to ten Meriones unguiculatus per group, except the ivermectin group with $0.2 \mathrm{mg} / \mathrm{kg}(n=4)$ detected up to the highest concentrations tested. Treatment with AAD 1566 did not increase the revertant numbers of any of the bacterial tester strains used. Thus, AAD $1566 \mathrm{did}$ not show evidence of a mutagenic potential under the experimental conditions used in this bacterial reverse mutation assay. Similar results were obtained in screening tests with AADs 96, 85, and 95 (data not shown).

Chromosome aberration test AAD 1566 produced a concentration-dependent decrease in the mitotic index. Based on the mitotic index data, the following concentrations of AAD 1566 were selected for analysis in the chromosomal aberration assay: without metabolic activation, 25.8, 33.4, $43.1 \mu \mathrm{g} / \mathrm{mL}$ (20-h continuous treatment) and 57.2, 81.8, $97.8 \mu \mathrm{g} / \mathrm{mL}$ (3-h treatment, 17-h recovery); with metabolic activation, $77.5,100.1,129.3 \mu \mathrm{g} / \mathrm{mL}$ (3-h treatment, 17-h recovery) and $81.8,117.0,139.9 \mu \mathrm{g} / \mathrm{mL}$ (3-h treatment, 17-h recovery). In the absence, as well as in the presence of metabolic activation, the aberration frequencies of cultures treated with AAD 1566 were all within the historical control range. No increase in the frequencies of polyploid cells was observed in the absence or presence of rat liver S9. In conclusion, AAD 1566 did not show any clastogenic potential under the test conditions used in the chromosomal aberration test with human peripheral blood lymphocytes.

Micronucleus test There were no clinical signs and no mortality of mice for AAD 1566. No cytotoxicity was 
Table 5 Efficacy of AADs against larval (L4)stages of various nematode species in sheep after oral application

\begin{tabular}{|c|c|c|c|c|c|c|c|c|}
\hline \multirow[t]{2}{*}{ AAD } & \multirow[t]{2}{*}{ Dose $(\mathrm{mg} / \mathrm{kg})$ of the active enantiomer } & \multicolumn{7}{|c|}{ Efficacy (\%) } \\
\hline & & $\mathrm{Hc}$ & $\mathrm{T}$ circ & $\mathrm{Ta}$ & Tc & $\mathrm{Cc}$ & Ns & $\mathrm{Co}$ \\
\hline 79 & 5.00 & 100 & 100 & 96 & 100 & 75 & 100 & 100 \\
\hline \multirow[t]{3}{*}{85} & 5.00 & 100 & 100 & 98.5 & 99.5 & 92 & 99.5 & 100 \\
\hline & 2.50 & 100 & 100 & 99 & 100 & 96 & 99 & 100 \\
\hline & 1.25 & 100 & 98 & 79 & 100 & 88 & 33 & 90 \\
\hline 93 & 5.00 & 76 & 68 & 73 & 100 & 65 & 50 & 100 \\
\hline \multirow[t]{2}{*}{94} & 5.00 & 100 & 100 & 99.5 & 100 & 95.5 & 100 & 99 \\
\hline & 2.50 & 100 & 100 & 99 & 100 & 97 & 90 & 97 \\
\hline \multirow[t]{2}{*}{95} & 5.00 & 100 & 100 & 99 & 100 & 97.5 & 100 & 100 \\
\hline & 2.50 & 100 & 100 & 97 & 100 & 97 & 76 & 100 \\
\hline \multirow[t]{3}{*}{96} & 5.00 & 100 & 100 & 100 & 100 & 96 & 100 & 100 \\
\hline & 2.50 & 100 & 100 & 100 & 100 & 92 & 100 & 100 \\
\hline & 1.25 & 100 & 100 & 96 & 100 & 80 & 46 & 95 \\
\hline \multirow[t]{2}{*}{1566} & 3.75 & 100 & 100 & 99 & 100 & 98 & 99 & 100 \\
\hline & 2.50 & 100 & 100 & 99 & 100 & 98 & 96 & 100 \\
\hline
\end{tabular}

All AADs, except the AAD 1566, were tested as racemic mixtures containing half of the active enantiomer; doses in the table have been calculated for the active enantiomer. AAD 1566 was tested as the purified active enantiomer. Each dose was tested in two to five infected sheep. Hc H. contortus, T circ Teladorsagia circumcincta, Ta T. axei, Tc T. colubriformis, Cc C. curticei, Ns N. spathiger, Co C. ovina

evidenced by the PCE/NCE ratio. There was no biologically relevant increase of the number of micronucleated PCEs indicating a lack of mutagenic potential.

Tolerability in sheep AAD 85 and AAD 96 did not reveal any side effects in the treated animals when administered at a dose of $50 \mathrm{mg} / \mathrm{kg}$ bodyweight. No deviations from normal values were observed in these sheep, and they stayed in good health during the entire study. AAD 85 and AAD 96 appear to be well tolerated by sheep after oral administration of a dose of $50 \mathrm{mg} / \mathrm{kg}$ bodyweight. Similarly, no relevant differences were observed or measured in any animals during the second tolerability study where AAD 1566 was evaluated. There was a transient loss in appetite (several hours) in the sheep treated at $125 \mathrm{mg} / \mathrm{kg}$ (50 time the probable minimum dose rate).

Table 6 Efficacy of AAD 96 and AAD 1566 against adult stages of resistant $H$. contortus in sheep

\begin{tabular}{|c|c|c|c|}
\hline \multirow[t]{2}{*}{ Drug/compound } & \multirow[t]{2}{*}{ Dose $(\mathrm{mg} / \mathrm{kg})$} & \multicolumn{2}{|l|}{ Worm counts } \\
\hline & & H. contortus Howick & H. contortus Mox/Fen Australia \\
\hline Ivermectin & 0.2 & 977 & nd \\
\hline Combination of & & 238 & nd \\
\hline Ivermectin + & 0.2 & & \\
\hline Albendazole + & 3.8 & & \\
\hline Levamisole & 7.5 & & \\
\hline AAD 96 & 2.5 & 0 & nd \\
\hline AAD 96 & 1.3 & 0 & nd \\
\hline Moxidectin & 0.2 & nd & 407 \\
\hline Combination of & & nd & 508 \\
\hline Moxidectin+ & 0.2 & & \\
\hline Fenbendazole + & 5.0 & & \\
\hline Levamisole & 7.5 & & \\
\hline AAD 96 & 1.3 & nd & 0 \\
\hline AAD 1566 & 2.5 & nd & 0 \\
\hline
\end{tabular}

Each dose was tested in two to three sheep. The sheep treated with the combination of drugs were used as the internal control for the sheep treated with the AADs. The dose of AAD 96 has been calculated for the active enantiomer (AAD 1566), which makes $50 \%$ of the racemic mixture AAD 96. $n d$ Not determined 


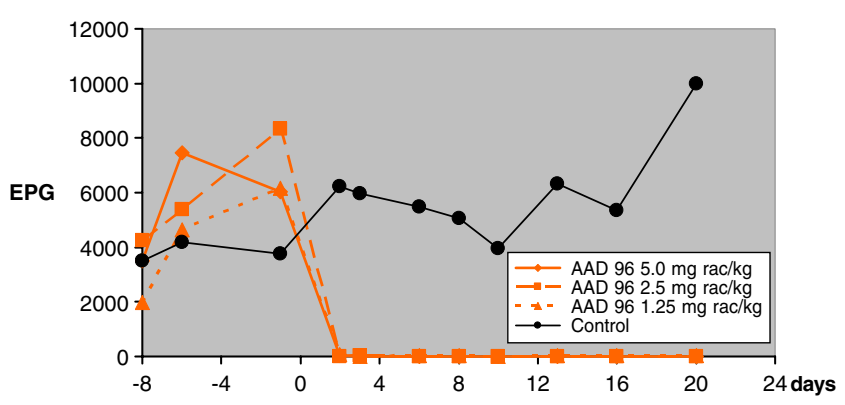

Fig. 1 Efficacy of AAD 96 against adult trichostrongyles in sheep determined by egg count reduction (mean of three sheep per group); treatment at day 0

\section{Discussion}

The discovery of the AADs as a new class of synthetic compounds with anthelmintic efficacy is only the first step to finally provide veterinarians and livestock farmers with an alternative for the control of drug-resistant gastrointestinal nematodes. As a next step, at least one AAD needs to be selected to enter a drug development program. Ideally, a development candidate combines best efficacy against all gastro-intestinal nematodes, including the resistant isolates with low toxicity and best tolerability. We followed the approach described by Prichard and Geary (2008) to evaluate previously described (Kaminsky et al. 2008) and herein described follow-up AADs for their potential as drug development candidates. The in vitro $\mathrm{EC}_{100}$ values of the AADs evaluated herein were higher than those of some previously tested AADs (Ducray et al. 2008). However, it was not possible to differentiate the AADs described herein on the basis of their in vitro activities since they were all in the same range. Differences in anthelmintic activity were however observed in gerbils. Here, the AADs 85, 95, and 96 expressed higher efficacy at both oral dosing of $0.32 \mathrm{mg} / \mathrm{kg}$ and subcutaneous dosing of $1 \mathrm{mg} / \mathrm{kg}$ than other AADs tested (Table 2; Kaminsky et al. 2008, Ducray et al. 2008). Further differences occurred in efficacy studies in sheep. All AADs eliminated $H$. contortus and T. circumcincta at a dose of $5 \mathrm{mg} / \mathrm{kg}$ except AAD 93 (Table 5). At a dose of $2.5 \mathrm{mg} / \mathrm{kg}$, AADs 85, 94, 95, 96, and 1566 (the active enantiomer in the racemic mixture of AAD 96) were $>90 \%$ effective against $C$. curticei, but only AADs 85, 96, and 1566 were $>90 \%$ effective against $N$. spathiger. A further comparison in cattle revealed that AAD 96 with its active enantiomer AAD 1566 was the most effective compound curing cattle infected with larval stages of $O$. ostertagi and $C$. oncophora at an oral dose of $3.8 \mathrm{mg} / \mathrm{kg}$ or adult stages at a topical dose of $5 \mathrm{mg} / \mathrm{kg}$ (Table 7). Efficacy studies in gerbils confirmed that only one enantiomer (AAD 1566) of the racemic mixture (AAD 96) expresses anthelmintic activity (Table 3 ).

Following the observation that AAD 1566 was one of the most effective AADs, it also met the other requirements for a drug development candidate. Essential for any new anthelmintic drug beyond the broad-spectrum efficacy will be the efficacy against drug-resistant, particularly multidrug-resistant nematodes. Both of the two most-suitable AADs, AAD 85a (active enantiomer in the racemic mixture of AAD 85) and AAD 1566, eliminated susceptible and multi-drug-resistant $H$. contortus in gerbils at the same dose (Table 4). These results were later confirmed in sheep. A dose of $2.5 \mathrm{mg}$ AAD $1566 / \mathrm{kg}$, which was required for broad-spectrum efficacy in sheep, was sufficient to cure sheep infected with each of two multi-drug-resistant $H$. contortus isolates (Table 6). None of the infected sheep were cured with either triple drug combination. The adult stages of the multi-drug-resistant $H$. contortus were eliminated in sheep with only half $(1.3 \mathrm{mg}$ active enantiomer of AAD 96/kg) of the broad-spectrum dose. The efficacy against multi-drug-resistant nematodes confirms the previous observations of other AADs (Kaminsky

Table 7 Efficacy of AADs in cattle

\begin{tabular}{|c|c|c|c|c|c|}
\hline \multirow[t]{2}{*}{$\mathrm{AAD}$} & \multirow[t]{2}{*}{ Dose (mg/kg) } & \multirow[t]{2}{*}{ Application route } & \multirow[t]{2}{*}{ Stage } & \multicolumn{2}{|c|}{ Efficacy (\%) against } \\
\hline & & & & O. ostertagi & C. oncophora \\
\hline 85 & 9.5 & Oral & $\mathrm{L} 4$ & 80 & 100 \\
\hline 94 & 9.5 & Oral & L4 & 100 & 100 \\
\hline \multirow[t]{4}{*}{96} & 9.5 & Oral & L4 & 100 & 100 \\
\hline & 7.5 & Oral & $\mathrm{L} 4$ & 100 & 100 \\
\hline & 5.0 & Oral & $\mathrm{L} 4$ & 99.5 & 100 \\
\hline & 3.8 & Oral & $\mathrm{L} 4$ & 98 & 100 \\
\hline \multirow[t]{4}{*}{1566} & 4.0 & Topical & L4 & 93 & 100 \\
\hline & 3.0 & Topical & L4 & 91 & 99 \\
\hline & 10.0 & Topical & Adult & 100 & 100 \\
\hline & 5.0 & Topical & Adult & 100 & 100 \\
\hline
\end{tabular}

AADs were given in all oral applications as racemic mixtures of the two enantiomers. Doses in the table have been calculated for the active enantiomer. AAD 1566 given topical was tested as the purified active enantiomer 
et al. 2008) and appears to be a common feature of this chemical class. The resistance-breaking ability indicates a new mode of action.

In addition to the evaluation of efficacy, basic toxicity and tolerability tests were conducted for selected AADs. All AADs appear to be of low toxicity to mammals as demonstrated by the results of the Ames, chromosome aberration, and micronucleus tests. Furthermore, for AAD $85 \mathrm{a}$ and 96, at doses ten times higher than the curative dose of $2.5 \mathrm{mg} / \mathrm{kg}$ for all tested gastro-intestinal nematodes species in sheep, no side effects were observed. There was only a transient loss of appetite at a 50 times higher than curative dose in sheep of AAD 1566. The observed good tolerability of the AADs in this study confirms the same observation with previously tested AADs (Kaminsky et al. 2008). The most likely reason for the selective action is the nematode-specific molecular target of AADs, which is not present in mammals. AADs interfere with a unique ACR23 nicotinic acetylcholine receptor subunit (Kaminsky et al. 2008), which belongs to the DEG-3 nematode-specific subfamily (Mongan et al. 2002).

The broad-spectrum efficacy of AAD 1566, monepantel, and the efficacy against resistant and multi-drug-resistant nematode isolates due to a new mode of action, complemented by the low toxicity to mammals and the excellent tolerability in sheep due to a nematode-specific target, render this $\mathrm{AAD}$ an anthelmintic drug development candidate. It remains subject to further evaluation if monepantel will become a commercially available anthelmintic product.

Acknowledgments We are most grateful to Simone Mulhauser, Jacques Lambert, and Estelle Pradervand for excellent technical assistance. We thank Arthur Redpath and Emma Duffy for thorough review and comments on the manuscript.

Open Access This article is distributed under the terms of the Creative Commons Attribution Noncommercial License which permits any noncommercial use, distribution, and reproduction in any medium, provided the original author(s) and source are credited.

\section{References}

Anziani OS, Suarez V, Guglielmone AA, Warnke O, Grande H, Coles GC (2004) Resistance to benzimidazole and macrocyclic lactone anthelmintics in cattle nematodes in Argentina. Vet Parasitol 122:303-306

Besier RB (2007) New anthelmintics for livestock: the time is right. Trends in Parasitol 23:21-24

Besier RB, Love SCJ (2003) Anthelmintic resistance in sheep nematodes in Australia: the need for new approaches. Aust J Exp Agric 43:1383-1391

Blake B, Coles GC (2007) Flock cull due to anthelmintic-resistant nematodes. Vet Rec 161:36

Chabala JC, Mrozik H, Tolman RL, Eskola P, Lusi A, Peterson LH, Woods MF, Fisher MH, Campbell WC, Egerton JR, Ostlind DA
(1980) Ivermectin, a new broad-spectrum antiparasitic agent. J Med Chem 23:1134-1136

Coles GC (1998) Drug-resistant parasites of sheep: an emerging problem in Britain? Parasitol Today 14:86-87

Coles GC, Hong C, Hunt KR (1991) Benzimidazole resistant nematodes in sheep in southern England. Vet Rec 128:44

Coles GC, Watson CL, Anziani OS (2001) Ivermectin-resistant Cooperia in cattle. Vet Rec 148:283-284

Conder GA, Jen L-W, Marbury KS, Johnson SS, Guimond PM, Thomas EM, Lee BL (1990) A novel anthelmintic model utilizing jirds, Meriones unguiculatus, infected with Haemonchus contortus. J Parasitol 76:168-170

Conder GA, Johnson SS, Guimond PM, Cox DL, Lee BL (1991) Concurrent infections with the ruminant nematodes Haemonchus contortus and Trichostrongylus colubriformis in jirds, Meriones unguiculatus, and use of this model for anthelmintic studies. J Parasitol 77:621-623

Ducray P, Gauvry N, Pautrat F, Goebel T, Fruechtel J, Desaules Y, Schorderet Weber S, Bouvier J, Wagner T, Froelich O, Kaminsky R (2008) Discovery of amino-acetonitrile derivatives, a new class of synthetic anthelmintic compounds. Bioorg Med Chem Lett 18:2935-2938

Echevarria F, Borba MFS, Pinheiro AC, Waller PJ, Hansen JW (1996) The prevalence of anthelmintic resistance in nematode parasites of sheep in Southern Latin America. Brazil. Vet Parasitol 62:199-206

Familton AS, Mason P, Coles GC (2001) Anthelmintic-resistant Cooperia species in cattle. Vet Rec 149:719-720

Gasbarre L, Smith L (2004) The development of cattle nematode parasites resistant to multiple classes of anthelmintics in a commercial cattle population in the U.S. American Association of Veterinary Parasitology Proceedings (2004); July, 20.

Ghisi M, Kaminsky R, Mäser P (2007) Phenotyping and genotyping of Haemonchus contortus isolates reveals a new putative candidate mutation for benzimidazole resistance in nematodes. Vet Parasitol 144:313-320

Gill JH, Redwin JM, Van Wyk JA, Lacey E (1995) Avermectin inhibition of larval development in Haemonchus contortus. Effects of ivermectin resistance. Int J Parasitology 25:463-470

Jackson F, Coop RL (2000) The development of anthelmintic resistance in sheep nematodes. Parasitology 120:S95-S107

Kaminsky R (2003) Drug resistance in nematodes: a paper tiger or a real problem ? Curr Opin Infect Dis 16:559-564

Kaminsky R, Ducray P, Jung M, Clover R, Rufener L, Bouvier J, Schorderet Weber S, Wenger A, Wieland-Berghausen S, Goebel T, Gauvry N, Pautrat F, Skripsky T, Froelich O, Komoin-Oka C, Westlund B, Sluder A, Mäser P (2008) A new class of anthelmintics effective against drug-resistant nematodes. Nature 452:176-180

Kaplan RM (2004) Drug resistance in nematodes of veterinary importance: a status report. Trends in Parasitol 20:477-481

Love SCJ, Neilson FJA, Biddle AJ, McKinnon R (2003) Moxidectinresistant Haemonchus contortus in sheep in northern New South Wales. Aust Vet J 81:359-360

Mejia ME, Fernandez Igartua BM, Schmidt EE, Cabaret J (2003) Multispecies and multiple anthelmintic resistance on cattle nematodes in a farm in Argentina: the beginning of high resistance ? Vet.Research 34:461-467

Mongan NP, Jones AK, Smith GR, Sansom MS, Sattelle DB (2002) Novel $\alpha 7$-like nicotinic acetylcholine receptor subunits in the nematode Caenorhabditis elegans. Protein Sci 11:1162-1171

OECD (1997a) Guideline for the testing of chemicals 471, bacterial reverse mutation test. Adopted 21st July 1997.

OECD (1997b) Guideline for the testing of chemicals 474, in vitro mammalian chromosome aberration test. Adopted 21st July 1997.

OECD (1997c) Guideline for the testing of chemicals 473, mammalian erythrocyte micronucleus test. Adopted 21st July 1997. 
Prichard RK, Geary TG (2008) Fresh hope to can the worms. Nature 452:157-158

Sargison ND, Jackson F, Bartley DJ, Moir ACP (2005) Failure of moxidectin to control benzimidazole-, levamisole- and ivermectinresistant Teladorsagia circumcincta in a sheep flock. Vet Rec 156:105-109

Traversa D, Paoletti B, Otranto D, Miller J (2007) First report of multiple drug resistance in trichostrongyles affecting sheep under field conditions in Italy. Parasitol Res 101:1713-1736

van Wyk JA, Malan FS, Randles JL (1997) How long before resistance makes it impossible to control some field isolates of Haemonchus contortus in South Africa with any of the modern anthelmintics. Vet Parasitol 70:111-122

Waghorn TS, Leathwick DM, Rhodes AP, Lawrence KE, Jackson R, Pomroy WE, West DM, Moffat JR (2006a) Prevalence of anthelmintic resistance on 62 beef cattle farms in the North Island of New Zealand. NZ Vet J 54:278-282
Waghorn TS, Leathwick DM, Rhodes AP, Lawrence KE, Jackson R, Pomroy WE, Moffat JR (2006b) Prevalence of anthelmintic resistance on sheep farms in New Zealand. NZ Vet J 54:271-277

Waller PJ (1999) International approaches to the concept of integrated control of nematode parasites in livestock. Int J. Parasitol 29:155-164

Wrigley J, McArthur M, McKenna PB, Mariadass B (2006) Resistance to a triple combination of broad-spectrum anthelmintics in naturallyaquired Ostertagia circumcincta infections in sheep. NZ Vet $\mathrm{J}$ 54:47-49

Wood IB, Amaral NK, Bairden K, Duncan JL, Kassai T, Malone JB Jr, Pankavich JA, Reinecke RK, Slocombe O, Taylor SM, Vercruysse J (1995) World Association for the Advancement of Veterinary Parasitology (WAAVP) second edition of guidelines for evaluating the efficacy of anthelmintics in ruminants (bovine, ovine, caprine). Vet Parasitol 58:181-213

Yue C, Coles GC, Blake N (2003) Multiresistant nematodes on a Devon farm. Vet Rec 153:604 